\title{
Determinación social del malestar psicológico y el estrés en hombres que ejercen violencia familiar en la Ciudad de México
}

\author{
Social determinants of psychological distress and stress \\ in men who perpetrate family violence in Mexico City
}

${ }^{1}$ Doctor en Ciencias en Salud Colectiva. Profesor investigador, Universidad Autónoma del Estado de Hidalgo, México. $\square$ (iD)

${ }^{2}$ Doctor en Salud Mental Comunitaria. Investigador y docente, Instituto de Salud Pública, Universidad Veracruzana, México. $\bowtie$ iD
RESUMEN El objetivo es describir y analizar la determinación social del malestar psicológico y el estrés en dos grupos de hombres de la Ciudad de México que asistían a programas reeducativos por violencia familiar. Para ello, se realizó un estudio no experimental, transversal, descriptivo con metodología cualitativa y enfoque interpretativo, en el que se aplicó un cuestionario y se realizaron grupos focales. Los síntomas de estrés reportados fueron dolores musculares; insomnio y pesadillas; náuseas, dolor de estómago e indigestión; dolores de cabeza, mareos, irritabilidad o mal humor. Los principales problemas que podrían estar generando esta sintomatología serían la economía personal y familiar; la salud de ellos y sus familiares y los malestares mentales, entre otros aspectos. Existen diferencias relacionadas con las condiciones de vida y los efectos de la violencia doméstica. Los abordajes que solo consideran la masculinidad hegemónica o el género para el trabajo con varones en sus diferentes condiciones y problemáticas, sin considerar la desigualdad social y, en especial, las condiciones de vida, pueden ser insuficientes para explicar y modificar las causas de las afectaciones generadas y experimentadas por los varones.

PALABRAS CLAVES Determinantes Sociales de la Salud; Hombres; Violencia Familiar; México.

\begin{abstract}
The social determinants of psychological distress and stress are described and analyzed in two groups of men attending reeducation programs for family violence in Mexico City. A non-experimental, descriptive, transversal study was conducted employing a qualitative methodology and an interpretive approach, in which questionnaires were utilized and focus groups were held. Symptoms of stress that were reported included muscle aches, insomnia and nightmares, headaches or dizziness, irritability or bad mood, nausea, stomach pain and indigestion. The principal issues that could be identified as the root of these symptoms included personal and family finances, their own health or that of their family members, and mental distress, among others. Differences with respect to living conditions and the effects of domestic violence were present. We argue that initiatives directed at men and their particular conditions and problems which are based on a hegemonic view of masculinity and gender are likely to be limited in their capacity to explain and modify the causes of situations generated by and experienced by men.
\end{abstract}

KEY WORDS Social Determinants of Health; Men; Domestic Violence; Mexico. 


\section{ANTECEDENTES}

Debido a los mandatos de la masculinidad hegemónica o dominante ${ }^{(1,2)}$, muchos hombres minimizan sus problemas de salud física y psíquica, y no solicitan o retrasan la búsqueda de atención médica o psicológica ${ }^{(3)}$. La necesidad de ayuda o atención es negada por muchos varones y otras personas de su entorno debido a que es incompatible con la idea más compartida de masculinidad $y$, por lo tanto, inconsistente con el poder y los privilegios "masculinos"(4). Cuando acuden a la atención médica, sus problemas pueden ser invisibilizados por los criterios diagnósticos dominantes, por ejemplo, el caso de la depresión a modo masculino ${ }^{(3,5,6)}$. A lo anterior se suma el hecho de que algunos médicos varones se resisten a diagnosticar enfermedades a otros hombres, por sus supuestos de género, minimizando el dolor y negando la vulnerabilidad de los hombres, al atribuirles la fuerza como principal característica ${ }^{(8,9)}$. Muchos de estos problemas de salud masculinos invisibilizados y sus causas resultan convergentes con las características del modelo de sujeto ideal para el modo de producción capitalista, al normalizar la competencia entre varones, el desempeño individual, las jerarquías y el logro personal-material a "cualquier costo"(10).

Debido a la socialización masculina ${ }^{(11)}$, varias problemáticas de los hombres no existen como problemas de salud en los registros médicos o en las estadísticas de salud pública. Un balance regional para las Américas $^{(12)}$ muestra una esperanza de vida de 5,8 años menos para los hombres y una notable sobremortalidad masculina por muertes violentas -homicidios, accidentes, suicidios y relacionadas al trabajo-, por situaciones de consumo -alcohol y otras drogas- y por VIH-sida. Esta sobremortalidad, vista desde lo interseccional, es aún más marcada por razones de etnia, orientación sexual, así como en trabajos peligrosos o en la situación de desempleo.

Para este trabajo, se considera que los varones son sujetos genéricos con identidades, prácticas y relaciones, producto de construc- ciones sociales y no hechos de la naturaleza. En ese sentido, la masculinidad y la hombría no tienen un significado fijo ni trascendente, sino que participan de una disputa social, al nivel de la significación en los diferentes contextos sociales e históricos, que es una de las dimensiones de las luchas sociales y políticas. Este planteamiento se asume para el término masculinidad, aunque no siempre se hace para el término hombre, que a menudo en los propios estudios de género aparece como un término obvio, evidente por sí mismo ${ }^{(13)}$. Teniendo en cuenta lo anterior y tratando de evitar la posible polisemia de la palabra hombre para cada sujeto, se usará el concepto de varón y hombre indistintamente como sinónimos del cuerpo con características sexuales de la especie humana, y dando por sentado que dicha identidad ha ido asumida por ellos mismos, exceptuando los casos en que el propio texto señale un sentido diferente.

La salud colectiva ha contribuido a la mejor comprensión de los determinantes del proceso salud-enfermedad y a la definición de alternativas de intervención a los problemas sanitarios $^{(14)}$. Desde el género, las diferentes formas de ser varón implican trayectorias similares, distintas $y$, a la vez, particulares en el proceso salud-enfermedad-atención ${ }^{(15)}$. La Organización Mundial de la Salud ${ }^{166}$ considera que la salud mental es un estado de bienestar, en el que el individuo es consciente de sus propias capacidades, puede afrontar las tensiones normales de la vida, puede trabajar de forma productiva y fructífera, y es capaz de hacer una contribución a su comunidad. Además, destaca que la salud mental está relacionada con la prevención de trastornos mentales y el tratamiento y rehabilitación de las personas afectadas por dichos trastornos pero, principalmente, con la promoción del bienestar, definiciones que forman parte de la definición general de salud como un "estado de completo bienestar físico, mental y social, y no solamente la ausencia de afecciones o enfermedades" ${ }^{\prime \prime 17)}$.

En ese sentido, se considera que la salud psíquica incluye la evaluación subjetiva positiva o deseable que cada sujeto hace sobre el estado de su proyecto de vida, en función de 
las condiciones materiales de su existencia, sus deseos, aspiraciones, planes y proyecciones personales y colectivas. Así, además de las condiciones objetivas, la subjetividad de las personas juega un papel fundamental para comprender su experiencia de malestar y su afectación a la salud psíquica ${ }^{(18)}$. Visto desde la perspectiva de género y aunado a los malestares y afectaciones a la salud mental que experimentan y niegan los varones debido a que los consideran consistentes con los mandatos de la masculinidad, muchos refieren malestares vinculados con el agotamiento del modelo hegemónico de masculinidad ${ }^{(19)}$, además, del originado por sus condiciones materiales de vida.

La división sexual del trabajo es génesis y reflejo de la especialización humana a partir del sexo $y$, al igual que otras esferas de análisis por género, muestra su carácter histórico y conformador de relaciones sociales, interpersonales de poder e identitarias $y$, al mismo tiempo, también afectan grupal e individualmente según la pertenencia a una u otra clase social dentro de un modo de producción determinado, o a la condición laboral que se guarde dentro de este ${ }^{(20)}$. Algunos investigadores explican el recrudecimiento de las condiciones de vida a partir de los efectos del pensamiento económico neoliberal, cuyo principal objetivo es la obtención de mayores ganancias a niveles nacionales y mundiales ${ }^{(21)}$. Sobre la relación entre la crisis económica, las condiciones materiales de vida y la salud mental en Europa, Raventós ${ }^{(22)}$ comenta que uno de sus efectos es la grave repercusión en la salud de las personas, y más concretamente en la salud mental, siendo los inmigrantes y los grupos más marginados los que presentan mayor riesgo de padecer enfermedades mentales. Olavarría ${ }^{(23)}$ reflexiona, en el contexto laboral chileno, sobre los procesos de globalización y su vínculo con temas sociales, señalando que es principalmente a los hombres a quienes se los somete $-y$ aceptan- a un desarraigo nacional y estructuración a cambio de beneficios materiales y simbólicos, lo que implica el uso inescrupuloso de recursos y métodos para incrementar el lucro de sus compañías, y la falta de responsabilidad por las consecuencias de sus decisiones en las personas, comunidades, cultura, recursos naturales y derechos humanos, económicos y sociales. Garduño $^{(24)}$ por su parte, señala que el estudio de la salud en el trabajo en el contexto neoliberal y la perspectiva de género son perspectivas en proceso de construcción, y que existe una falta de planteamientos teóricos y prácticos que permitan comprender el papel de las masculinidades y feminidades en la causalidad de los daños a la salud.

Vargas y Caraveo ${ }^{(25)}$ observaron que, antes de que las manifestaciones del proceso salud-enfermedad-atención formen parte de los diagnósticos psiquiátricos en México, es posible identificar manifestaciones emocionales y somáticas, muchas de los cuales tienen una génesis social, independientemente de la taxonomía popular de la que formen parte. En ese sentido, Tena ${ }^{(26)}$ señala que los problemas afectivos de los varones relacionados con malestares en sus empleos tienen que ver con dos grandes estructuras de poder: el sistema económico globalizado de reciente emergencia y los esquemas hegemónicos sobre lo masculino y lo femenino. En una investigación-acción que piloteó un dispositivo grupal de atención psicológica al malestar por la crisis de empleo en hombres, los varones identificaron esferas individuales y sociales de la afectación por la crisis, y se identificó un posible efecto indeseado de trabajar con los varones para modificar sus subjetividades y conductas genéricas dominantes, sin reflexionar críticamente sobre las causas económico-políticas y laborales que generan las condiciones de vida que los enferman y determinan sus relaciones sociales ${ }^{(27)}$.

Desde un programa de atención a hombres realizado por de Keijzer ${ }^{(28)}$, se investigaron las trayectorias y los dilemas que los hombres enfrentan en sus relaciones de pareja y en su esfuerzo por dejar la violencia en las relaciones de pareja y familia, encontrando que los cambios en las relaciones de género y las dramáticas condiciones de pobreza, desempleo, crimen organizado y ascenso de las muertes ligadas a la lucha en contra del narcotráfico tienen una influencia 
en la violencia doméstica. El trabajo de Cantoral(29), al abordar las desigualdades familiares y su malestar por razones de género frente a las transformaciones socioculturales del país, señala que la consideración de los malestares que expresaron tanto mujeres como hombres puede servir para evitar el acercamiento parcial con el que comúnmente se realiza la atención psicológica, y abordar el malestar cotidiano. Borislavovna ${ }^{(30)}$ concluye en su estudio que los diferentes niveles de depresión reportados por mujeres y hombres jóvenes implican la necesidad de tomar en cuenta al género como determinante específico de riesgo para psicopatología, y que la identidad tradicional de género es poco saludable para ambos sexos, tendiendo manifestaciones y efectos específicos para cada uno. Fleiz $z^{(6)}$, identifica que los principales eventos de vida para la génesis del malestar depresivo en hombres mexicanos voluntarios y con diagnóstico de depresión mayor fueron: la pérdida de la pareja, de la salud, del empleo o la adicción al trabajo, la pérdida de seres queridos, así como la experiencia de abuso sexual. Las manifestaciones físicas del malestar fueron: dolores musculares, problemas para conciliar el sueño, falta de energía y descuido en el arreglo personal. Las expresiones emocionales fueron: tristeza, irritabilidad, soledad, ansiedad e inseguridad. Otras manifestaciones estuvieron vinculadas a la represión de sus sentimientos: no permitirse llorar, no mostrar vulnerabilidad ante los demás, no exteriorizar los sentimientos y aguantar el dolor ante las pérdidas. La investigación de Sánchez ${ }^{(7)}$ reconoce la diversidad de cuadros depresivos de los varones y se enfoca en la descripción de la narcisista, para explicar cómo el perder o no alcanzar ideales que se inscribieron en la subjetividad como masculinos puede generar una sensación de no ser valioso, perfecto o no ser "lo suficientemente hombre". Relaciona el fenómeno de la globalización con el engrandecimiento de valores, como el poder económico, el éxito y la competitividad, los que que se han configurado como ideales a los cuales aspirar, y resultan congruentes con los ideales dominantes de género para los hombres. Señala que las condiciones de precariedad social y económica prevalentes hacen que el hecho de alcanzar o mantener estos ideales resulte no tan solo difícil, sino fuente de tensión y conflicto psíquico, pudiendo derivar en padecimientos como la depresión de tipo narcisista. Finalmente, el estudio de Granados $^{(31)}$ realiza un abordaje cualitativo sobre las enfermedades mentales y el género, y observa formas específicas de expresión del sufrimiento psíquico por no satisfacer sus objetivos y proyectos de vida, así como de la capacidad para allegarse los recursos necesarios para la consecución de tales proyectos, siendo enfrentado de manera distinta por varones y mujeres. En la Tabla 1 , se muestra un concentrado de las causas sociales y psicológicas de las afectaciones a la salud psíquica de los varones según los estudios citados.

Para la Organización Mundial de la Salud $^{(17)}$, los determinantes sociales de la salud son "las circunstancias en que las personas nacen, crecen, viven, trabajan y envejecen, y los sistemas establecidos para combatir las enfermedades. A su vez, esas circunstancias están configuradas por un conjunto más amplio de fuerzas: económicas, sociales, normativas y políticas". Desde la salud colectiva, la desigualdad social que determina muchas de esas fuerzas no se considera necesaria, natural e inevitable, sino como una condición histórica que puede ser modificable desde un espíritu de justicia y búsqueda de la igualdad social de las colectividades, búsqueda que va a la par de la protección de los derechos humanos y de la satisfacción de otras necesidades básicas, producto de la sociedad particular en que están insertas las personas ${ }^{(32)}$. La jerarquización de determinantes sociales propone que los niveles más complejos sobredeterminan a los de menor complejidad, y que el nivel social subsume al biológico y psicológico. De esta forma, el estudio de lo social es imprescindible para explicar cómo se constituye el proceso de salud-enfermedad, porque solo así se pueden identificar sus determinantes últimos que son los de mayor poder explicativo y de predicción ${ }^{(33,34)}$. El malestar psicológico es una vivencia subjetiva 
con dificultad para expresarse en palabras, ya que no alude directamente a un síntoma de enfermedad, aunque refiere a que se "está mal" de cierta forma y en relación con algo ${ }^{(18)}$; es una sensación de padecimiento psíquico o noción transicional subjetivaobjetiva, interna-externa, que no reproduce la clásica división dicotómica sano-enfermo, sino que se introduce como un tercer término asociado al conflicto y crisis $^{(35)}$. Forma parte de las condiciones de vida producto el desarrollo económico alcanzado por una sociedad en un tiempo y lugar determinados, $y$ que influyen en el nivel de vida y calidad de vida del sujeto, mismo que se puede medir a través de indicadores de ingreso y consumo. En el abordaje de la calidad de vida, los indicadores de corte objetivo resultan necesarios, pero requieren de un complemento indispensable: la expresión de los valores sociales en el individuo y cuán importantes resultan para él; es decir, el bienestar psicológico: la interacción entre lo social y lo psicológico ${ }^{(17)}$.

El estrés psicosocial es producto del ambiente, es decir, de la organización social, el apoyo social, los aspectos socioeconómicos, el estatus marital, el rol laboral, el género y otros elementos implicados tanto en el origen como en las consecuencias de las experiencias estresantes, induciendo efectos directos sobre la salud e indirectos a través de la modificación de los estilos o hábitos de vida: consumo de sustancias legales e ilegales, hacer poco ejercicio físico, seguir una dieta poco saludable, etc., ${ }^{(36)}$. El estrés se relaciona con la percepción de estímulos amenazantes y/o relacionados con la necesidad de actuar con fines de sobrevivencia, ante los cuales, un organismo requiere de ajustes adaptativos que le permitan mantener su condición interna estable ante los cambios externos (homeostasis). Un estresor es una situación que perturba la homeostasis, produce la activación del sistema nervioso vegetativo -glándulas suprarrenales, sistema cardiovascular, respiratorio y metabólico- y ciertos procesos en el sistema nervioso central, principalmente en estructuras cerebrales relacionadas con las emociones -amígdala, hipotálamo, hipocampo, septum, corteza prefrontal, porciones altas del tallo cerebral, entre otras-, y se relaciona con las respuestas de enfrentamiento que dispone cada individuo. Ante una excesiva, repetitiva y prolongada exposición al agente estresante, permanecen activados los mecanismos adaptativos (alostasis), transformándose de un ajuste protector y transitorio a otro con alto poder patogénico ${ }^{(37)}$.

Tres posibles tipos de estrés son producto de momentos específicos con diferente intensidad: estrés reciente, el crónico y el cotidiano. Desde el marco clínico, la respuesta de los sujetos a las situaciones estresantes se conoce como afrontamiento al estrés, es decir, respuestas cognitivas y comportamentales que median las relaciones entre la percepción del estrés y la consiguiente adaptación somática y psicológica ${ }^{(38)}$. Los estresores sociales no afectan por igual ni a todas las personas, ni a todos los grupos, y ello se debe a: 1) la percepción del estresor; 2) la capacidad de individuo para controlar la situación; 3) la preparación del individuo por la sociedad para afrontar los problemas, y; 4) la influencia de los patrones de conducta aprobados en la sociedad. Estos recursos son un potencial para la acción, y algunas de sus formas son: el apoyo social, el locus de control, la percepción de control, la autoeficacia, la autoestima, el sentido del optimismo, entre otros, destacando el papel que juega el contexto social e institucional en que se desarrollan los eventos para que los sujetos empleen una u otra ${ }^{(38)}$.

A partir de los estudios revisados, en la Tabla 1 se muestra la relación entre el ambiente de los hombres y la determinación las formas subjetivas y manifestaciones somáticas de la afectación. Dado que el malestar psicológico y el estrés psicosocial no infringen las reglas sociales, debido a que sus manifestaciones somáticas y subjetivas son naturalizadas y normalizadas, las afectaciones a la salud de los hombres relacionadas con la masculinidad hegemónica neoliberal $^{(1,10)}$ en sus ambientes multidimensionales específicos $^{(39)}$, no son catalogadas como un problema social o de salud pública(33), exceptuando algunos casos, por ejemplo, los casos de expresión del malestar por medio de la violencia familiar. 


\section{Tabla 1. Causas de la afectación a la salud psíquica de los varones y las manifestaciones subjetivas y somáticas.} Ciudad de México, 2014.

Causas de la afectación a la salud psíquica de los varones

a) La globalización de la economía y la política afectan no solo estas áreas, sino también la vida cotidiana de las personas. Las corporaciones transnacionales organizan y definen territorios y poblaciones, que también estructuran las subjetividades y los cuerpos de las personas. En su funcionamiento óptimo, el modo de producción capitalista busca la mayor ganancia con efecto en el incremento de las desigualdades sociales, y en las crisis de las empresas transnacionales, estas se vuelven crisis de las economías locales -y de las personas- debido a que guardan una misma lógica de funcionamiento y dominio.

b) Las condiciones sociales afectan directamente la salud, ya que quienes presentan los peores índices de salud mental son las personas de clase trabajadora, quienes poseen menor educación formal, pertenencia a la tercera edad, habitantes de zonas rurales, los inmigrantes pobres y las personas que experimentan mayor vulnerabilidad y desigualdad social.

c) La pobreza produce estrés prolongado debido a la inseguridad económica, aislamiento social y falta de perspectivas de futuro. Los efectos se acumulan a lo largo de la vida y aumentan las posibilidades de sufrir depresión y una pobre salud mental a mayor edad. Se observa el evidente aumento de la pobreza y el desempleo ocurridos durante las últimas décadas en México, con influencia en la violencia doméstica.

d) El género es uno de los determinantes que influyen en la distribución diferencial de las enfermedades y de los padecimientos mentales. La identidad tradicional de género da origen a problemas colectivos de salud y a formas específicas de expresión de sufrimiento psíquico, el cual es enfrentado de manera específica por los varones. Además, se presenta malestar en diferentes grupos debido a las transformaciones socioculturales del país, teniendo como una esfera de manifestación las relaciones de pareja y familiares.

e) La crisis económica afecta gravemente a quienes padecen patologías mentales severas, y las personas en general pueden ser víctimas de problemáticas serias de salud mental derivadas de las huelgas, las jubilaciones anticipadas, el mal funcionamiento o quiebra de los negocios propios, la falta de créditos bancarios accesibles y las expropiaciones, los recortes a los servicios sociales y de salud mental, la desaparición de los fondos de pensiones, la falta de vivienda digna y la violencia social asociada a la pobreza.

f) La seguridad material es el centro casi absoluto de la vida contemporánea para las mayorías. La oferta de bienes materiales es infinita y su consumo responde a necesidades que, para algunos, pueden ser satisfechas y, para otros, se relaciona con experiencias de insatisfacción respecto de su proyecto de vida.

g) La crisis de empleo de los varones y los problemas afectivos asociados se relacionan con el sistema económico globalizado de reciente emergencia que se caracteriza por una competencia estresante entre sujetos, el empleo precario o desempleo, y los esquemas hegemónicos sobre la distribución sexual de trabajo.

h) Ciertos eventos de vida se asocian al malestar depresivo en hombres: la pérdida de la pareja, la ruptura familiar, ciertos problemas de salud, la adicción al trabajo, la pérdida de seres queridos y la experiencia de abuso sexual en la infancia.

Manifestaciones subjetivas y somáticas

a) Problemas de salud pública: desnutrición y consumo de alimentos menos nutritivos; incremento de la población sin hogar; el desempleo y lo que comporta: pobreza relativa, pérdida de autoestima, comportamientos poco saludables, aumento de suicidios, drogadicción, depresión, mayores tasas de suicidios y alcoholismo que, a su vez, se asocia con mayor violencia contra la pareja; mortalidad aumentada; salud infantil deteriorada; violencia, producto de la frustración y desesperación por la crisis de empleo y la pobreza; problemas de salud ambiental y laboral; injusticia social y violación de derechos humanos; y problemas de disponibilidad y accesibilidad de los servicios de atención médica.

b) Psicopatologías contemporáneas: tendencias narcisistas; incremento de tendencias esquizoides; aumento en perturbaciones psicosomáticas; mayores niveles de soledad e incomunicación; angustias y ansiedades que origina el miedo; desvalorización de la propia persona; anomia; indefensión y subordinación ante un poder invisible; crisis en relaciones interpersonales; dependencias incapacitantes al alcohol y otras sustancias; suicidio consumado; fundamentalismos; el refugio en las tecnologías y los medios masivos de comunicación; y aumento de actividades deportivas para paliar síntomas.

c) Estados crónicos que se convierten en trastornos psiquiátricos: se pasa de un estado agudo de ansiedad a un estado crónico de alarma continua, debido a agentes estresantes psicológicos y sociales, y ello comporta determinados procesos más graves como la depresión.

d) Depresión masculina: dolores musculares; problemas para conciliar el sueño; falta de energía; aislamiento; soledad y descuido en el arreglo personal. Las expresiones emocionales pueden ser: tristeza, irritabilidad, soledad, ansiedad e inseguridad, no permitirse llorar, no mostrar vulnerabilidad, no exteriorizar los sentimientos, aguantar el dolor ante las pérdidas, ataques de enojo y sentimientos hostiles hacia sí mismos. La mayoría de los síntomas de las depresiones 0 antecedentes del episodio no son consultados con nadie y, por lo tanto, no reciben tratamiento.

e) Consecuencias de la crisis de empleo: autoadquirir un estigma cultural y social; la búsqueda de empleo se percibe como actividad humillante; un replanteamiento de las funciones sociales ante la familia, la sociedad y la propia identidad; una experiencia de pérdida de poder en las relaciones sociales; $y$ prácticas de autocastigos.

f) Restricciones emocionales: se suprimen una serie de formas emocionales del malestar que son necesarias para la expresión del sufrimiento psíquico; nega la necesidad de ayuda; falta de medidas de autocuidado y/o negarse a solicitar atención médica.

g) Burnout: originado por la exigencia constante del trabajo si el individuo se siente incapaz o tiene dificultades para controlar sus emociones; el estrés crónico producido puede generar ese síndrome.

h) Sintomatología que precede a la psicopatología afectiva, ansiosa o en relación con abuso de sustancias: dolores físicos constantes; antecedentes de malestares emocionales; antecedentes de "ataques al corazón"; trastornos médicos simultáneos; y una percepción negativa de su estado de salud mental.

i) Patología asociada al estrés: enfermedades cardiovasculares, hipertensión, úlcera péptica, dolores musculares, asma, jaquecas, pérdida de la calidad de vida y otros problemas de salud.

j) Sobremortalidad masculina: de los varones de entre 15 y 64 años que mueren en México, casi la mitad se debe a muertes violentas como: accidentes, agresiones (homicidios), autolesiones (suicidios), cirrosis hepática (consumo excesivo de alcohol).

Fuente: Elaboración propia basada en los trabajos de Fleiz ${ }^{(6)}$, Sánchez ${ }^{(7)}$, Guinsberg ${ }^{(21)}$, Raventóo ${ }^{(22)}$, Olavarría ${ }^{(23)}$, Garduño $0^{(24)}$, Vargas y Carave ${ }^{(25)}$, Tena ${ }^{(26)}$, Bolaños $^{(27)}$, de Keijzer ${ }^{(28)}$, Cantoral ${ }^{(29)}$, Borislavovna ${ }^{(30)}$, Granados ${ }^{(31)}$. 


\section{METODOLOGÍA}

Se trata de un estudio no experimental, transversal, descriptivo, con metodología cualitativa y enfoque interpretativo ${ }^{(40)}$ desde el campo de la salud colectiva, a partir de la distribución diferencial del proceso de saludenfermedad por género centrada en varones. Se realizó en dos grupos de hombres que asisten a programas reeducativos para detener su violencia familiar, con el objetivo de describir y analizar la experiencia subjetiva con relación a su malestar psicológico y estrés determinados socialmente, y la expresión de esa afectación por medio de actos de abuso hacia familiares. En este trabajo, se abordan únicamente los siguientes objetivos correspondientes a la determinación social del malestar psicológico y el estrés psicosocial: a) identificar las principales causas del contexto social amplio que determinan su malestar psicológico y estrés, y; b) conocer las formas cognitivas, emocionales y manifestaciones somáticas que reportan sobre su malestar psicológico y el estrés.

Como parte de las técnicas de recopilación de datos, se utilizaron estrategias convergentes piloteadas previamente: un cuestionario conformado por apartados sobre datos generales; inventarios clínicos estandarizados y no estandarizados; y grupos focales, cuyas sesiones fueron audiograbadas. El levantamiento de datos concluyó en junio de 2014. Para el manejo y análisis de la información, se realizó la transcripción de los audios, la construcción de matrices metodológicas de categorías teóricas y temáticas, códigos pre-elaborados para fragmentar la información, paquetería de office y el software ATLAS TI para el manejo de datos cualitativos de investigación. Se llevó a cabo un análisis de contenido para acceder al conocimiento de diversos aspectos y fenómenos respecto del objeto de estudio ${ }^{(41)}$.

Con el cuestionario se buscó conocer los datos sociodemográficos y de salud de los participantes, los problemas de la vida cotidiana que les generan mayor molestia, la presencia de síntomas de estrés, antecedentes de maltrato familiar en la infancia y determinar la posible "tipología de agresor". En los grupos focales, se realizaron discusiones diseñadas para obtener las percepciones sobre los temas de interés ${ }^{(42,43)}$; la guía de entrevista permitió la apertura a las narraciones sobre las causas y manifestaciones del malestar psicológico y estrés de los sujetos, así como los elementos que permiten el abuso expresivo. Además, posibilitó la recuperación de procesos y elementos no considerados en el planteamiento teórico-metodológico de este trabajo.

De los dos grupos participantes, el perteneciente al ámbito semirural o denominado "Sur", enfrentaba consecuencias institucionales del abuso, al asistir obligatoriamente por un tribunal administrativo a su propio programa de tratamiento, y posiblemente enfrentaban algún procedimiento legal específico; el otro, del ámbito urbano, identificado como "Centro", se trató de hombres autoreferidos o voluntarios que asistían a una organización de la sociedad civil que únicamente enfrentaban el deterioro de la relación de pareja o familiar, lo que implicaría cierto grado de angustia por la separación u otra consecuencia.

\section{Participantes}

Se trató de un muestreo teórico de hombres ya identificados o autoidentificados como violentos, y que asisten a grupos previamente conformados y pertenecientes a una institución pública y a una organización social: la primera, en un contexto semirural y, la segunda, en el ámbito urbano. Se incluyó a los hombres mayores de edad que ejercieron violencia familiar y asistían a un programa reeducativo grupal para detener dichas prácticas, que mantuvieran o hubieran mantenido previamente una relación de pareja o familiar, y que aceptaran participar voluntariamente en el estudio. Se excluyó a los que fueran pacientes psiquiátricos sin tratamiento o disfuncionales y a los que se negaran a participar en el estudio. En la Tabla 2 se presentan los datos generales de los hombres participantes del estudio por grupo. 
Tabla 2. Datos generales de los hombres participantes del estudio. Ciudad de México, 2014.

\begin{tabular}{|c|c|c|c|c|c|c|c|c|c|}
\hline \multirow{6}{*}{$\begin{array}{l}\text { 今 } \\
\text { 高 }\end{array}$} & Seudónimo & Edad & $\begin{array}{l}\text { Estado } \\
\text { civil }\end{array}$ & $\begin{array}{l}\text { Tiene } \\
\text { Pareja }\end{array}$ & Hijos/as & Escolaridad & Ocupación & $\begin{array}{l}\text { Ingresos } \\
\text { mensuales }\end{array}$ & $\begin{array}{l}\text { Servicio de } \\
\text { Salud }\end{array}$ \\
\hline & Andrés & 48 & Casado & No & 1 & Preparatoria & Oficios & $\begin{array}{l}\text { Entre } \$ 2.501 \mathrm{y} \\
\$ 5.000\end{array}$ & IMSS \\
\hline & Edgar & 43 & Casado & Sí & 2 & Carrera técnica & Comerciante & $\begin{array}{l}\text { Entre } \$ 2.501 \text { y } \\
\$ 5.000\end{array}$ & $\begin{array}{l}\text { Seguro } \\
\text { Popular }\end{array}$ \\
\hline & Pablo & 25 & Soltero & No & - & Preparatoria & Desempleado & No tiene & IMSS \\
\hline & Joaquín & 20 & Soltero & No & - & $\begin{array}{l}\text { Preparatoria } \\
\text { incompleta }\end{array}$ & Estudiante & No tiene & No tiene \\
\hline & Rafael & 47 & Casado & No & - & $\begin{array}{l}\text { Preparatoria } \\
\text { incompleta }\end{array}$ & Comerciante & $\begin{array}{l}\text { Entre } \$ 2.501 \mathrm{y} \\
\$ 5.000\end{array}$ & No tiene \\
\hline \multirow{9}{*}{$\begin{array}{l}\text { 은 } \\
\text { 인 } \\
\text { 을 }\end{array}$} & Francisco & 46 & Casado & Sí & 2 & Licenciatura & $\begin{array}{l}\text { Empleado tiempo } \\
\text { completo }\end{array}$ & No contestó & PEMEX \\
\hline & Víctor & 38 & Soltero & Sí & - & Posgrado & $\begin{array}{l}\text { Trabaja en el sector } \\
\text { social }\end{array}$ & Más de $\$ 16.000$ & No tiene \\
\hline & Alfredo & 47 & $\begin{array}{l}\text { Unión } \\
\text { libre }\end{array}$ & Sí & 3 & $\begin{array}{l}\text { Secundaria } \\
\text { incompleta }\end{array}$ & $\begin{array}{l}\text { Empleado tiempo } \\
\text { completo }\end{array}$ & $\begin{array}{l}\text { Entre } \$ 8.001 \text { y } \\
\$ 12.000\end{array}$ & ISSSTE \\
\hline & Omar & 48 & Soltero & No & - & Carrera técnica & $\begin{array}{l}\text { Empleado medio } \\
\text { tiempo }\end{array}$ & $\begin{array}{l}\text { Entre } \$ 2.501 \mathrm{y} \\
\$ 5.000\end{array}$ & No tiene \\
\hline & Sergio & 33 & $\begin{array}{l}\text { Unión } \\
\text { libre }\end{array}$ & Sí & 1 & Secundaria & $\begin{array}{l}\text { Empleado tiempo } \\
\text { completo }\end{array}$ & $\begin{array}{l}\text { Entre } \$ 2.501 \text { y } \\
\$ 5.000\end{array}$ & No Tiene \\
\hline & Ernesto & 40 & Soltero & No & - & Posgrado & $\begin{array}{l}\text { Voluntario de medio } \\
\text { tiempo en Hospital }\end{array}$ & $\$ 2.500$ o menos & No Tiene \\
\hline & David & 22 & Soltero & Sí & 1 & $\begin{array}{l}\text { Bachillerato } \\
\text { incompleto }\end{array}$ & $\begin{array}{l}\text { Empleado tiempo } \\
\text { completo }\end{array}$ & $\begin{array}{l}\text { Entre } \$ 2.501 \mathrm{y} \\
\$ 5.000\end{array}$ & ISSSTE \\
\hline & Manuel & 24 & Soltero & No & - & $\begin{array}{l}\text { Licenciatura } \\
\text { incompleta }\end{array}$ & Estudiante & $\$ 2.500$ o menos & IMSS \\
\hline & Pedro & 32 & Soltero & No & - & Licenciatura & $\begin{array}{l}\text { Empleado tiempo } \\
\text { completo }\end{array}$ & $\begin{array}{l}\text { Entre } \$ 8.001 \text { y } \\
\$ 12.000\end{array}$ & No tiene \\
\hline
\end{tabular}

Fuente: Elaboración propia.

IMSS= Instituto Mexicano del Seguro Social; PEMEX= Petróleos Mexicanos; ISSSTE= Instituto de Seguridad y Servicios Sociales de los Trabajadores del Estado.

Del contexto institucional emergieron particularidades por grupo: a) los hombres del grupo Sur presentaron al inicio de las entrevistas una actitud más reservada y, en general, sus narraciones fueron más dirigidas a responder los temas explorados por el entrevistador y emergieron más elementos de la terapia obligatoria a la que se someten cuando abordaron su experiencia personal. Los del grupo Centro, además de ser mayor en número, estuvieron más abiertos a discutir otros elementos emergentes -temas sociales y cambios, tensiones en relaciones de género-, además de los planteados por el entrevistador, siendo más abundantes sus narraciones sobre su experiencia personal en torno a lo explorado en el estudio; b) en este mismo grupo, tres de los participantes eran coordinadores de estos dispositivos de intervención, habiendo sido originalmente usuarios, y trabajaban en sensibilización y capacitación en temas de género. Sin embargo, ello no obstaculizó su participación, debido a que tienen una experiencia similar a la de cualquier otro varón de la Ciudad de México en torno a su exposición a los determinantes sociales de la salud-enfermedad; c) a diferencia de otros varones, los de ambos grupos presentaron cierto desarrollo de habilidades para identificar elementos cognitivoconductuales y sexistas, involucrados en los eventos de maltrato y desarrollados en su asistencia al grupo, lo que permitió narraciones más específicas sobre sus experiencias, así como debates sobre las relaciones interpersonales de género. 


\section{RESULTADOS}

\section{Cuestionario}

Las escalas correspondientes a la lista de problemas fueron: salud, economía, trabajo, vivienda, relaciones sociales, ocio, familia, psicológica y se agregó un apartado llamado otros. En la Tabla 3 se presentan las similitudes entre grupos en torno a los aspectos más y menos problemáticos en sus vidas.

Los trastornos del sueño y del estómago fueron los elementos de mayor afectación en salud que se reportaron en ambos grupos; además del sentirse físicamente cansados, que también se reportó como un problema que afecta intensamente a los hombres del grupo Centro. Para el grupo Sur, la falta de dinero para el ocio y las aficiones era uno de sus principales problemas, a diferencia del Centro, que reportó el aumento creciente de deudas como un elemento que generaba mayor afectación. Entre los reactivos que ambos señalaron como generadores de mayor molestia respecto de la economía estaba el dinero insuficiente para las necesidades básicas y los gastos inesperados. Cabe destacar que, en general, se reportó una mayor molestia y afectación en esta área en comparación con las otras listas o áreas de vida cuestionadas.

Los principales aspectos laborales que afectaban la vida cotidiana de ambos eran la necesidad de una mayor experiencia o formación y las prisas y el estrés. Los que resultaron diferentes fueron: para el Sur, que en su mayoría trabajaban por cuenta propia, la necesidad de mayor libertad en el trabajo; $y$, para el Centro, el temor a perderlo, dado que en su mayoría tenían trabajos fijos de tiempo completo o medio tiempo. Las similitudes que compartían respecto de los problemas que los afectaban intensamente en el área vivienda eran que estaban demasiado lejos del trabajo o escuela, asunto común para los habitantes en la Ciudad de México y su área conurbada. Respecto de las diferencias, el Sur presentaba mayores molestias sobre factores externos a su vivienda, tal como tener vecinos indeseables; el Centro, por su parte, manifestó el hecho de que existan cosas que precisaban una reparación, es decir, factores inherentes a la mejora del propio inmueble. Cabe destacar, que esta área presentó el menor malestar o afectación en comparación con las otras áreas exploradas.

La violencia presente en las relaciones de pareja o familiares puede relacionarse con el hecho de fracasar en una aventura amorosa y no entenderse bien con algunas personas, eran los elementos que compartían ambos grupos respecto de lo que les generaba mayor afectación en las relaciones sociales. Los principales elementos que afectaban su vida cotidiana y que presentaban diferencias por grupo eran: para el Sur, sentirse solos; y, para el Centro, ser vulnerable a las críticas de los demás.

Tabla 3. Similitudes entre grupos en la lista de problemas. Ciudad de México, 2014.

\begin{tabular}{l|l|l}
\hline Área & Los que más afectan & Los que menos afectan \\
\hline Salud & Trastornos del sueño / Trastornos del estómago & - \\
\hline Economía & Dinero insuficiente para las necesidades básicas / Gastos inesperados & Tener demasiadas cargas financieras \\
\hline Trabajo & Necesidad de una mayor experiencia o formación / Prisa y estrés & - \\
\hline Vivienda & Está demasiado lejos del trabajo o escuela & $\begin{array}{l}\text { Tener una vivienda en condiciones desagradables / Malas } \\
\text { relaciones con el propietario }\end{array}$ \\
\hline Relaciones sociales & $\begin{array}{l}\text { Fracaso o estar fracasando en una aventura amorosa / No entenderse } \\
\text { bien con algunas personas }\end{array}$ & No tener muchos amigos \\
\hline Ocio & Necesidad de unas vacaciones & - \\
\hline Familia & $\begin{array}{l}\text { Sentirse atrapado en una situación familiar dolorosa / Estar } \\
\text { preocupado por un miembro de la familia }\end{array}$ & - \\
\hline Psicológica & $\begin{array}{l}\text { Sentirse muy deprimido algunas veces / Sentirse muy enfadado / } \\
\text { Preocuparse }\end{array}$ & - \\
\hline Fuente: Elaboración propia. &
\end{tabular}


La necesidad de unas vacaciones era el elemento que compartían ambos grupos como de mayor afectación en el área ocio. Algunos de los elementos principales resultaron diferentes. Por ejemplo, en el Sur, la incapacidad para pensar en algo divertido para hacer y, en el Centro, el deseo de viajar y tener pocas ocasiones para disfrutar de la naturaleza, muestra que, mientras en un caso se hacía referencia a la dificultad de realizar actividades placenteras, en el otro, a la frustración por no realizar actividades placenteras específicas. Esta área presentó mayores diferencias por grupo.

Para el área familia, se apreciaron posibles consecuencias de la violencia, dado que ambos grupos reportaron sentirse atrapados en una situación familiar dolorosa y estar preocupados por un miembro de la familia como elementos en común que más afectaban. En el grupo Sur, las excesivas discusiones en la casa y el sentirse incapaz de ser abierto y honesto con los miembros de la familia fueron dos de los principales elementos que generaban molestia, a diferencia de los reportados por el grupo Centro, que se centraban en la inseguridad o temor a perder a la pareja y estar irritado por las costumbres de un miembro de la familia. Es posible que la dinámica de la violencia doméstica sea diferente o se encuentre en una etapa distinta para cada grupo, si consideramos que dentro de las principales afectaciones para el grupo Sur mandatado por ley- se encuentran discusiones excesivas y la pérdida de la confianza y, para el Centro, el temor a una separación o alejamiento y la molestia por conflictos cotidianos. Destaca una alta afectación en esta área en comparación con las otras.

Los problemas comunes del área psicológica que más afectan su salud mental son: sentirse muy deprimido algunas veces, sentirse muy enfadado y preocuparse. Las diferencias reportadas para los principales problemas son: la falta de motivación para el grupo Sur, y el sentirse muy nervioso para el grupo Centro. Al explorar algún otro tema que posiblemente les causara malestar y que no se abordó en las listas de problemas, solo en el grupo Centro se obtuvieron algunas respuestas: "vivencia de un accidente catastrófico", "no poder concretar un proyecto muy deseado", así como "la falta de privacidad de tus asuntos dentro de la familia".

A partir de los resultados de la lista de problemas y el inventario de síntomas de estrés, se observan los principales elementos que determinan socialmente el malestar psicológico y estrés de estos varones, así como las formas cognitivas, emocionales y manifestaciones corporales de tales procesos, entre los que se destacan el área económica y las manifestaciones en cuerpo y psique. Además, de los 28 síntomas de estrés explorados en la escala, se presentan los diez síntomas más reportados por cada grupo. Cabe destacar que, en términos de porcentaje global por grupo, el grupo Sur reporta el $43 \%$ de presencia de los síntomas explorados y el grupo Centro, el $25 \%$. Ello implica casi un $20 \%$ de diferencia entre uno y otro, siendo el Sur el más afectado.

En la Tabla 4, se presenta el lugar que ocupan las listas de problemas según su afectación por grupo, señalando en primer lugar la economía, seguida por las áreas psicológica y salud, como esferas de afectación común, destacando a la familia para el grupo Sur, así como las relaciones sociales en menor medida para el Centro.

\section{Entrevista grupal}

Respecto al trabajo remunerado, las narraciones de los hombres de ambos grupos se dirigieron a varios aspectos y en diferentes sentidos. Sin embargo, cuando se los cuestionó directamente por la relación entre esas condiciones y su malestar psicológico o estrés, sus respuestas se focalizaron en algunos puntos que se sintetizan en la Tabla 5. Los fenómenos sociales señalados con color, son los que se presentaron para ambos grupos, y el orden en el que se presentan es en el que emergieron en cada grupo. Se puede apreciar que, en ambos, se señaló la expectativa del rol tradicional de hombre-padre-proveedor, al que los varones son presionados o se autopresionan para cumplir, como causa común de las afectaciones psíquicas-corporales, lo 
Tabla 4. Principales problemas que generan malestar y síntomas por grupo. Ciudad de México, 2014.

\begin{tabular}{|c|c|c|c|c|c|c|}
\hline \multicolumn{4}{|c|}{ Grupo Sur } & \multicolumn{3}{|c|}{ Grupo Centro } \\
\hline №. & Temas & $\begin{array}{l}\text { Respuestas } \\
\text { positivas (\%) }\end{array}$ & $\begin{array}{l}\text { Principales síntomas de estrés } \\
(43 \%)\end{array}$ & Temas & $\begin{array}{l}\text { Respuestas } \\
\text { positivas (\%) }\end{array}$ & $\begin{array}{l}\text { Principales síntomas de estrés } \\
(25 \%)\end{array}$ \\
\hline 1 & Familia & 78 & Dolores musculares & Economía & 59 & Dolores musculares \\
\hline 2 & Economía & 63 & Insomnio y pesadillas & Psicológica & 53 & Insomnio y pesadillas \\
\hline 3 & Psicológica & 54 & Cambio en las conductas habituales & Salud & 54 & Garganta y boca seca \\
\hline 4 & Salud & 43 & Sudoración profusa & $\begin{array}{l}\text { Relaciones } \\
\text { sociales }\end{array}$ & 47 & Cambios de apetito \\
\hline 5 & $\begin{array}{l}\text { Relaciones } \\
\text { sociales }\end{array}$ & 43 & $\begin{array}{l}\text { Náuseas, dolor de estómago e } \\
\text { indigestión }\end{array}$ & Ocio & 50 & Estreñimiento o diarrea \\
\hline 6 & Ocio & 40 & Dolores de cabeza o mareos & Familia & 31 & Dolores de cabeza o mareos \\
\hline 7 & Trabajo & 34 & Irritabilidad o mal humor & Trabajo & 30 & Irritabilidad o mal humor \\
\hline 8 & Vivienda & 26 & Depresión & Vivienda & 18 & $\begin{array}{l}\text { Tensión muscular, torceduras } \\
\text { musculares y tics }\end{array}$ \\
\hline 9 & - & - & $\begin{array}{l}\text { Incremento en el número de } \\
\text { accidentes menores }\end{array}$ & - & - & $\begin{array}{l}\text { Náuseas, dolor de estómago e } \\
\text { indigestión }\end{array}$ \\
\hline 10 & - & - & $\begin{array}{l}\text { Pensamientos de apuro y falta de } \\
\text { concentración }\end{array}$ & - & - & Fatiga, dormir en exceso \\
\hline
\end{tabular}

Fuente: elaboración propia basada en los datos obtenidos con el cuestionario.

Nota: los ocho temas listados para ambos grupos son las áreas que resultaron similares en el inventario "Lista de problemas". Para los principales síntomas de estrés, se presentan los diez más frecuentes por grupo.

que indica las creencias tradicionales de género y las condiciones de trabajo precarias como los principales determinantes sociales de su malestar psicológico y estrés.

En cuanto a los servicios de salud y otras necesidades básicas, se identificaron fenómenos sociales comunes relacionados con el acceso a los servicios de salud y la insatisfacción de necesidades básicas que afectan su salud mental y/o física, y que se señalan con color en la Tabla 5. Cabe destacar que, aunque no se nombró de igual manera, ambos grupos comparten la insatisfacción de necesidades básicas debido a la falta de recursos económicos, por lo tanto, esta se muestra como un claro determinante social de la afectación a su salud. Además, señalaron las malas condiciones de los servicios de salud, el desgaste producto del apoyo que brindan a familiares ante estas condiciones y sus implicancias negativas para la esfera laboral, así como la falta de cobertura de varias necesidades básicas para sus grupos familiares. En aquellos que tienen mejores condiciones de vida, se destaca la insatisfacción respecto de la falta de recursos para la diversión personal y el esparcimiento familiar.
Con relación al apoyo social y los programas gubernamentales, ambos grupos identificaron la relación que guardan estas áreas con su malestar psicológico y estrés. Cabe destacar que de forma específica no se mencionaron los mismos fenómenos pero, de forma general, coincidieron en señalar las condiciones materiales de vida y la carencia de ciertos programas sociales como determinantes sociales de su malestar psicológico y estrés. Además, se aprecia que, de manera particular, los varones del grupo Centro percibieron ciertos cambios históricos de género institucionalizados, en los que no hay servicios dirigidos a los varones, como un posible determinante social de su afectación.

Respecto a los cambios de género y los programas dirigidos a mujeres, ambos grupos señalaron que el origen de su malestar psicológico o estrés se encuentra en las relaciones de pareja, y solo el grupo Centro señaló a los programas que apoyan a mujeres cuando se habló de los programas públicos. Es decir, aunque presentan algunas diferencias, se observa que las narraciones se dirigen principalmente a los cambios e insatisfacciones en 
Tabla 5. Temas de las narraciones por área explorada y grupo. Ciudad de México, 2014.

Grupo Sur Grupo Centro

Relación entre las condiciones del trabajo remunerado y el malestar psicológico 0 estrés

La dificultad de mantener cierto nivel o estatus social deseado para el grupo familiar

La falta temporal de solicitudes para el trabajo en los oficios

El rol tradicional de hombre-padre-proveedor al que los varones son presionados o se autopresionan a cumplir

Trabajar en el transporte público y/o ser usuario del servicio público de transporte Habituarse a la responsabilidad de un trabajo remunerado, sus características específicas, y/o la autoexigencia en la tarea a desempeñar

Las características indeseables del entorno geográfico donde se encuentra el empleo y el centralismo en el Distrito Federal de las instituciones y autoridades nacionales más importantes

El rol tradicional de hombre-padre-proveedor al que los varones son presionados o se autopresionan a cumplir

Temor y malestar familiar que es detonado por el incumplimiento del rol tradicional de proveedor ante las crisis de empleo

Relación entre necesidades insatisfechas de salud y otras básicas con el malestar psicológico y el estrés

Las malas condiciones de los servicios de salud

El apoyo que brindan a familiares ante las malas condiciones de los servicios de salud, y las implicaciones negativas para la esfera laboral

La frustración experimentada ante la no expresión de malestar al personal de salud por las malas condiciones de los servicios

La falta de cobertura de necesidades básicas del grupo familiar

La autopercepción de incumplir con la expectativa el rol tradicional de proveedor
Las malas condiciones de los servicios de salud

Estrés producto del temor a que un familiar se enferme y se exponga a las malas condiciones de los servicios de salud

El apoyo que brindan a familiares ante las malas condiciones de los servicios de salud, y las implicaciones negativas para la esfera laboral

La negación de la enfermedad y/o síntomas para evitar asistir a los servicios de salud

Las limitaciones en las necesidades básicas de diversión personal y de esparcimiento familiar

La inaccesibilidad a una vivienda propia y digna

Relación del apoyo social y los programas gubernamentales con el malestar psicológico y el estrés

La información transmitida por televisión sobre la mejora en las condiciones de vida generales, que consideran no se refleja en su cotidianidad

Las malas condiciones del desarrollo nacional que consideran es producto de la elección de malos gobernantes

La desaparición de algunos programas gubernamentales asistenciales y el mal uso de otros vigentes
Las condiciones del transporte público y el tráfico vehicular

La imposibilidad de adquirir una vivienda en zonas céntricas y sin problemas de delincuencia

La falta de difusión de los programas reeducativos para hombres

La falta de apoyos para los padres solteros

La percepción de exclusión de todo tipo de servicio por parte de las instituciones que ofrecen programas para las mujeres

Relación de los cambios de género y los programas dirigidos a mujeres con el malestar psicológico y el estrés

El acceso a una mayor instrucción formal y al trabajo remunerado por parte de la pareja mujer y la modificación del orden de poder en la relación

Las expectativas incumplidas para el hombre y la mujer sobre los roles tradicionales de género

El proceso de cambio ante el acceso al trabajo remunerado por parte de la pareja mujer y la modificación del orden de poder en la relación

Cumplir con las expectativas sobre el ideal de hombre en parejas heterosexuales

La percepción de pérdida de poder-dominación ante las mujeres en la relación de pareja

La percepción de pérdida de poder-valía ante las mujeres a nivel social debido a cambios recientes

Otros procesos generadores de malestar psicológico y estrés

El temor de ser víctima de la delincuencia y del crimen organizado

La corrupción de servidores públicos y dificultades en el pago de impuestos

El aumento de la competencia en el comercio

El deficiente servicio público para el mantenimiento y reparación de calles y el uso de los recursos públicos con fines partidistas

El cobro de cuotas y el mal uso de recursos en las escuelas públicas

La tensión entre padres separados debido al uso del dinero en la manutención de hijos/as

El temor al incumplimiento del proyecto personal

Fuente: elaboración propia basada en los datos obtenidos en el grupo focal.
El temor de ser víctima de la delincuencia y del crimen organizado

La corrupción de servidores públicos

El deficiente servicio público para el mantenimiento y reparación de calles

Las demandas de género a los varones en los distintos espacios sociales

La demanda a los varones para realizar actividades productivas o de tal importancia que generen estrés, como parte de una masculinidad ideal 
las relaciones interpersonales hombre-mujer.

En cuanto a otros procesos generadores de malestar psicológico y estrés que no se abordaron en la guía de entrevista, se observaron diferencias y similitudes. Las diferencias más notorias señalan que los del grupo Sur identificaron causas de su malestar provenientes de su actividad remunerada, mientras que los del grupo Centro reportaron malestares o estresores producto de ciertos mandatos sociales de género. Los procesos que resultaron comunes apuntaron a la descomposición social e institucional que afecta a todo el país, en formas de violencia, criminalidad, corrupción e impunidad, que se potencian para generar múltiples experiencias de victimización.

\section{DISCUSIÓN-CONCATENACIÓN}

Inicialmente, surgen algunas preguntas sobre los malestares y síntomas de estrés reportados y la salud de los hombres. Algunos autores desde el ámbito de la salud mental han reflexionado sobre las posibles psicopatologías o problemáticas masculinas que experimentan los hombres y que afectan a otras personas ${ }^{(5,44)}$, tomando como eje principal la masculinidad hegemónica ${ }^{(1)}$ y sus manifestaciones en privilegios de género y abuso de poder viciado(4) en la construcción de la identidad, experiencias y prácticas de los varones, acuñando propuestas conceptuales tales como: malestares masculinos, trastornos por indiferencia a otros/as o a sí mismo, abusos de poder y violencias, y trastornos por temeridad excesiva ${ }^{(5)}$, por mencionar las categorías generales. Partiendo de esa lógica clasificadora para conceptualizar las manifestaciones subjetivas y somáticas del malestar psicológico y el estrés, encontradas en este estudio, independientemente de las diferencias por grupo y recuperando los elementos comunes en torno a la determinación social de la afectación y sus manifestaciones en hombres ¿cuáles serían los conceptos más precisos para nombrar el malestar reportado en los signos y síntomas observados en estos varones?; ¿se destacaría su origen estructuralsocial en tal denominación o se haría únicamente referencia a la disfuncionalidad de los sujetos en la esfera familiar, del trabajo o en la comunidad? Por otra parte, ¿esta experiencia sería exclusiva de los varones que ejercen violencia familiar o podría extenderse a la generalidad de los hombres de la Ciudad de México, o de otras ciudades grandes, expuestos a los determinantes sociales de la salud-enfermedad que se exploraron y mencionaron? Si así fuese, ¿sería objeto de estudio de la salud pública y tendría una respuesta social organizada, o estaría normalizada debido a que no genera crisis en los intereses más sensibles del Estado ${ }^{(33)} \mathrm{O}$ de una sociedad capitalista?

Sobre la determinación social del malestar psicológico y el estrés, destaca que el área económica resultó la más importante para ambos grupos, en comparación con los otros procesos sociales presentados. Se comprende que esta actividad y su carga emocional tan intensa ${ }^{(19,26,27)}$, está ligada al rol de proveedor económico del grupo familiar, en su función de patriarca protector y responsable de un grupo de personas, todo ello determinado por la división sexual del trabajo $^{(19,12)}$, que les otorga el poder de mando y los "derechos" que acompañan a la autoridad de los varones. De igual manera, el malestar en el propio cuerpo y mente se señaló como afectaciones que los molestan de manera importante, que deben ser considerados como efecto de otras causas, más que una causa en sí $^{(32)}$. Algunos de estos determinantes sociales podrían ser la preocupación por la economía, el ámbito laboral, la violencia y delincuencia social, además de las afectaciones producto de los ejercicios de violencia familiar, por ejemplo: arrepentimiento y culpa, tratando de reconciliarse o culpando a la pareja, y ante el miedo al abandono debido a la dependencia emocional que muchos de estos hombres presentan ${ }^{(45)}$; además, se pueden presentar consecuencias negativas en la salud de la pareja, hijos e hijas y la dinámica familiar, que aumenta las posibilidades de separación y el temor de los hombres ${ }^{(46,47)}$. El grupo perteneciente a la zona semirural, con 
peores condiciones de vida, así como con posiblemente mayor afectación por la violencia ejercida, reportó el área familiar como la que principalmente les genera molestia y con mayor intensidad; estos datos son similares a los reportados en otros estudios sobre la relación entre los mayores índices de pobreza en la población, mayores problemas de salud, mayor presencia de estrés y de violencia familiar ${ }^{(48)}$. Asimismo, sobre las relaciones sociales y familiares como determinantes sociales de la salud-enfermedad, este grupo refirió mayores afectaciones, aunque la idea de ruptura familiar resultó un temor importante en ambos grupos.

La determinación social de esta afectación psíquica-corporal, muestra un ambiente social multidimensional con condiciones de trabajo precario, temor ante el desempleo y la crisis masculina de empleo, además de toxicidad de sus entornos geográficos y problemas económicos ${ }^{(32)}$. Presenta causas particulares de la afectación debido a la presencia de procesos estructurales, culturales de género y de la zona geográfica, que se articulan de manera compleja, potencializando la afectación psíquica-corporal en la salud de los varones de ambos grupos estudiados. Las deficiencias en satisfactores de necesidades básicas, en sus relaciones sociales y en la atención a la salud; el temor a la afectación de sus actividades remuneradas y el ocultamiento de sus síntomas; la insatisfacción de necesidades materiales propias y para el grupo familiar, y la frustración en proyectos personales ${ }^{(18)}$, son indicadores objetivos y subjetivos de una deficiente calidad de vida de estos hombres, que se relaciona con el proceso de determinación social de su malestar psicológico y estrés.

Las experiencias de insatisfacción y malestar en tono al ámbito laboral, señalan sus condiciones cambiantes en torno a la división sexual del trabajo y la adversidad socioeconómica, que se traduce en obstaculizar el cumplimiento del estereotipos de género masculino: la precariedad laboral y económica en la familia, la autopercepción de incumplir con el rol tradicional de proveedor/protector, y la percepción de pérdida de autoridad y poder masculino ante cambios en los roles de género en el espacio público ${ }^{(26,27)}$. Esta afectación potenciada por otros estresores ${ }^{(36)}$ muestra las formas en que algunos problemas sociales, conflictos interpersonales, malestares humanos y genéricos, se articulan en una concatenación contextual, en la que la violencia contra las mujeres es solo uno de los posibles problemas ${ }^{(28)}$, que se debe comprender de forma compleja y atender de manera integral.

Los cambios histórico-culturales de género y los programas públicos dirigidos a mujeres fue el tema que más debatieron en un grupo, posiblemente porque la violencia de pareja producto de la desigualdad de género es parte de sus discusiones semanales. Algunos cambios en los roles de pareja resultaron un determinante social de su malestar, y ello podría reflejar: a) una reacción a la modificación del orden de poder entre géneros; b) su percepción ante las múltiples carencias en sus condiciones materiales de vida y, por lo tanto, en el rol "masculino" de proveedor ${ }^{(4)}$; c) una mezcla de ambas: al observar que a ellos no se los apoya como a sus parejas mujeres con recursos económicos -becas- para mejorar sus necesidades básicas insatisfechas, y al percibir que reciben un trato injusto por parte de las instancias públicas que, a la vez, los deja en "desventaja" frente a ellas, como si se tratara de una competencia entre sexos o lucha de poderes.

Señalaron, como otras causas de su afectación: el mal desempeño y la corrupción del gobierno federal y local; la delincuencia y el crimen organizado; el deficiente mantenimiento y reparación de calles y alumbrado público; las condiciones de competencia y precariedad del mercado laboral; los problemas con la expareja por el pago de los alimentos a sus hijos/as, y; angustias y frustraciones sobre sus proyectos personalesmasculinos. A diferencia de recibir el apoyo de programas públicos, estos varones cuentan únicamente con elementos no institucionales de una posible red social para atenuar el efecto del malestar psicológico y el estrés general $^{(37)}$, como el producido por la violencia ejercida. Sobre las acciones públicas en 
este sentido, solo reportaron la intervención reeducativa que recibieron de manera obligada en un centro específico para atender la violencia familiar.

En términos de estrés, se puede decir que identificaron en menor medida a sus estresores cotidianos asociados al ámbito laboral, la falta de actividades de ocio y vacaciones, así como el malestar producido por habitar en zonas geográficas tóxicas causantes de malestares $^{(36)}$. La modificación de roles tradicionales de género y la insatisfacción de ciertas necesidades básicas se asocian al malestar psicológico, causado por no ver materializado el proyecto de pareja ${ }^{(45,46)}$ o la vida que pensaron para sí mismos ${ }^{(18)}$, y con el estrés crónico, ya que muchos de sus conflictos de relación de pareja se han mantenido y/o sofisticado con el tiempo. También es posible considerar la presencia del estrés agudo o reciente, causado por la separación de la pareja o por la amenaza de ello en los últimos meses $^{(37)}$. La percepción de los varones del estudio sobre las causas de su malestar omite las variables provenientes de los niveles superiores de su entorno social amplio como modo de producción, altas tasas de desempleo, pobreza, ingresos bajos, así como otras del nivel personal-relacional: falta de autocuidado, creencias sexistas que los favorecen o perjudican y que avalan el uso de la violencia, tal como sucede en gran parte de la población ${ }^{(33)}$. Concretamente, las manifestaciones somáticas y subjetivas que resultaron comunes para ambos grupos de hombres fueron: dolores musculares, insomnio y pesadiIlas, dolores de cabeza o mareos, irritabilidad o mal humor y náuseas, dolor de estómago e indigestión. Desde la salud colectiva, estas expresiones patológicas en los hombres se consideran manifestaciones corporales y subjetivas de procesos sociales y culturales multinivel con carácter histórico ${ }^{(10)}$.

Respecto del locus de control y las respuestas de afrontamiento ${ }^{(38)}$, estos hombres consideraron que los cambios en los roles de las mujeres en el espacio público es una situación que no pueden modificar, aunque les genere malestar ${ }^{(45)}$. En este sentido, cabría preguntarse si esta es una percepción generalizada en los hombres de la Ciudad de México o particular de esta población; si es diferente según el tema o área relacional del que se trate; si varía por grupo de edad, clase social, orientación sexual, etnia u otra condición, y; si las respuestas a estas preguntas podrían ser relevantes para entender algunos actos de la violencia contra las mujeres en los espacios públicos.

Al contrastar las manifestaciones subjetivas y somáticas de los varones de este trabajo con la sintomatología o afectaciones reportadas por otros estudios $(6,7,21,22,23,24,25,26,27,28,29,30,31)$, se encontraron formas constantes de la afectación en varones a partir de procesos sociales recientes. Estos datos podrían ser problematizados en su contraste con otras cifras oficiales en salud o con, por ejemplo, estudios sobre las principales enfermedades de los hombres en áreas urbanas de México, los principales motivos de atención en los centros de salud y en consultorios médicos privados, los medicamentos más vendidos en los diferentes tipos de locales expendedores de fármacos, las principales causas de muerte de los hombres, y cada una de estos temas en diferentes territorios geográficos, entre otros datos de relevancia que despierten interés de investigación en la salud de los hombres desde cualquier campo de conocimiento.

Sobre algunos apuntes para la investigación, se identificó que la mayor afectación en varias áreas, incluyendo la familia, fue en el grupo Sur. Ello puede deberse a las mayores consecuencias por la violencia ejercida y su potencialización con otras causas ${ }^{(48)}$, en comparación con el grupo Centro. Los resultados, al no ser generalizables, queda abierto el análisis epidemiológico y desde la investigación cualitativa con hombres que ejercen violencia familiar y quienes no lo hacen, en función de si los determinantes sociales de malestares o estrés serían similares en ambos casos; si presentan diferencias debido a su contexto social más próximo; y si existen factores de riesgo para la salud de los varones que sean comunes entre los hombres habitantes de un mismo territorio.

El poder explicativo de la salud colectiva, que ha incorporado paulatinamente los 
análisis por género basado principalmente en las mujeres y en ambos sexos, y muy poco en los hombres ${ }^{(24)}$, tiene mucho que aportar sobre las condiciones de clase social, de vida, género $u$ otros procesos que se relacionan con las causas de enfermedad y muerte de los varones, las complejas relaciones de estas con la violencia contra las mujeres, hombres u otras por razones de género, así como sobre la respuesta social organizada ante estos problemas de salud pública ${ }^{(9)}$.

\section{CONCLUSIONES}

Los síntomas de estrés que reportaron ambos grupos con la escala utilizada fueron: dolores musculares, insomnio y pesadillas, náuseas, dolor de estómago e indigestión, dolores de cabeza o mareos e irritabilidad o mal humor. También reportaron: cambio en las conductas habituales, sudoración profusa, depresión, incremento en el número de accidentes menores, pensamientos de apuro y falta de concentración, garganta y boca seca, cambios de apetito, estreñimiento o diarrea, tensión muscular, torceduras musculares, tics, fatiga o dormir en exceso. Cabe destacar que el grupo con peores condiciones de vida reportó casi un $20 \%$ más de síntomas en comparación con el otro que participó en el estudio. Los principales problemas que podrían estar generando esta sintomatología según el cuestionario utilizado, serían: la economía personal y familiar; la salud de ellos y sus familiares; los malestares mentales o área de psicología; las relaciones sociales; satisfacer el ocio; la familia; el trabajo, y su vivienda.

En las entrevistas focalizadas se abordaron algunos temas como posibles determinantes sociales del malestar y otros emergieron como tales: el trabajo remunerado, los servicios de salud y la insatisfacción de otras necesidades básicas fueron nombradas como las principales causas de la afectación mental. A partir de su percepción, entre los generadores de malestar, les siguieron las carencias en el apoyo social y en los programas gubernamentales, los cambios de género y los programas dirigidos a mujeres, y otros procesos que no se abordaron en la guía de entrevista, tales como: la descomposición social e institucional que afecta a todo el país en formas de violencia, la criminalidad, la corrupción y la impunidad, que se potencian para generar múltiples experiencias de malestar, estrés o victimización.

Respecto de la reflexión sobre la determinación social de la salud-enfermedad en los varones del estudio y las categorías género y clase social, es necesario considerar: 1) el hecho de reeducar a los hombres que ejercen violencia para detener los abusos y maltratos no eliminaría el malestar psicológico y estrés generado por la insatisfacción de sus necesidades básicas producto de la desigualdad social y otras variables contextuales; 2 ) en términos de la determinación social de la salud-enfermedad, es necesario considera ambas esferas -desigualdad de género y de clase social- con igual importancia, diferenciándolas en su comprensión teórica, pero no en sus dimensiones sociales y empíricas, ni en la concatenación con la experiencia de las personas; 3) una tercera -e incongruenteopción, sería combatir organizadamente los determinantes sociales de la desigualdad de género y la violencia contra la pareja mujer y, al mismo tiempo, omitir la crítica a los determinantes sociales de la desigualdad social, la violencia estructural y entre hombres; 4) debido a que la mitad de los participantes afirman que no cuentan con seguridad social en salud, independientemente de que por ser habitantes de la Ciudad de México tienen derechohabiencia en los servicios locales, se identifica la presencia de una experiencia de vulnerabilidad y desamparo en caso de enfermedad para ellos y sus familias, la cual puede tener origen en la falta de información, pero también en la percepción de condiciones de insuficiencia en la seguridad social en salud.

La determinación social del malestar psicológico y el estrés no se presenta únicamente a partir de las condiciones estructurales, ya que se identificaron experiencias que se alejan de las reportadas por la mayoría de los hombres expuestos a estas condiciones generadas por la hegemonía Occidental, 
mostrando la diversidad de la experiencia humana dentro de los procesos de determinación social de la salud-enfermedad, con la presencia de otros capitales subjetivos que determinan vivencias particulares y positivas o negativas en los sujetos, por ejemplo, los casos del voluntariado y la experiencia de incumplir el rol de proveedor de una casa propia, respectivamente.

Los hombres del estudio destacaron la ausencia de difusión masiva sobre espacios que atiendan a los varones a detener su violencia familiar y otras problemáticas emocionales que experimentan; la necesidad de derechos sociales para padres solteros, aunque no mencionaron la ausencia paterna en la crianza o la educación autoritaria de niños y niñas de muchos varones; finalmente, desean contar con prestaciones laborales y seguridad social como se daba en décadas anteriores, es decir, en la época del Estado de bienestar. Estas necesidades detectadas pueden resultar básicas y estratégicas para el impulso de acciones públicas con perspectiva de género dirigidas a los varones, además de brindar protección social mínima a los trabajadores como parte de la satisfacción de sus necesidades básicas, es decir, como parte de sus derechos humanos.

Señalaron la necesidad de contar con espacios públicos para facilitar la construcción de prácticas equitativas en las relaciones de pareja, conformados por grupos de mujeres y hombres, que aborden temas como: los cambios actuales en los roles de género; la sexualidad; la reproducción; y la crianza y educación de hijos/as. Se propone contar con acciones informativas o intervenciones básicas, que permitan comprender y abordar de una manera más adecuada la dirección del cambio en proceso para la igualdad de género; pero, sobre todo, facilitar la comprensión de lo que las mujeres en su contexto demandan de los hombres en las relaciones interpersonales, además de otras acciones preventivas de la educación estereotipada de género para los hombres.

Se muestra la necesidad de acciones públicas con enfoques explicativos del papel de la masculinidad hegemónica en varios problemas sociales y en la mala calidad de vida de los varones. Se considera necesario generar una agenda amplia de políticas públicas con perspectiva de género y derechos humanos para los hombres. Es decir, acciones públicas que no dejen de lado la satisfacción de sus necesidades básicas, teniendo como un eje principal la salud, y facilitar la comprensión de la dirección de los cambios sociales hacia la igualdad de trato y oportunidades para ambos sexos, además de abordar las violencias. Cabe mencionar que la agenda Suma por la igualdad ${ }^{(49)}$, elaborada con base en la experiencia de expertos y expertas mexicanas en el campo del trabajo con hombres, es una propuesta para avanzar sobre algunas de estas necesidades. Dicha agenda señala recomendaciones específicas que apuntan a cambios en la cultura de género, la violencia, la salud de los hombres y la corresponsabilidad en el cuidado.

Los abordajes que solo consideran a la masculinidad hegemónica o el género para el trabajo con varones en sus diferentes condiciones y problemáticas, sin considerar la desigualdad social y en especial, las condiciones de vida, pueden ser insuficientes para explicar y modificar las causas de las afectaciones generadas y experimentadas por los varones. Estas resultan similares a las limitaciones de las propuestas sobre la conciliación familiatrabajo, sin que existan las condiciones legales, institucionales y laborales para Ilevarlas a cabo. Por ello, es imprescindible un enfoque intereseccional de estos procesos.

A partir del presente estudio surgieron los siguientes cuestionamientos: ¿cómo nombrar, en términos de patologías, al grupo de signos y síntomas encontrados, que son similares a las afectaciones reportadas por otros trabajos realizados desde la salud pública, la medina social, la psicología clínica y la salud mental comunitaria para los varones? ¿Además de poder ser tipificados como parte de algún tipo de estrés en varones, sería importante considerar alguna clasificación del malestar psicológico que nombre a la frustración personal producto de causas socioestructurales? ¿La respuesta social organizada desde la mirada hegemónica estaría interesada 
en ello? Se propone una reflexión teórica y diagnóstica sobre las manifestaciones de los malestares y las patologías de los varones, que se dirija a escuchar y nombrar sus padecimientos y los problemas de salud con los que se relacionan, así como a identificar sus causas y soluciones en términos de una respuesta social organizada, pero también, a nivel político-estructural.

Es necesaria la reflexión crítica sobre el abandono de las instituciones públicas de salud en México, y el señalamiento de la falta del aumento de recursos federales y estatales para este rubro. Resulta prioritario impulsar una reforma estratégica en salud con recursos suficientes para una adecuada y universal atención con sentido humano, a diferencia de considerar la salud como una mercancía, lo que implicaría que en el caso de muchas enfermedades crónicas y degenerativas, quienes posean mayores recursos monetarios podrán obtener mayor atención especializada en salud, y quienes cuenten con menos recursos económicos, podrán comprar pocos servicios para su salud y la de sus dependientes.

Debido a que la salud colectiva desarroIla propuestas teóricas y metodológicas sobre la determinación social de la salud-enfermedad y la respuesta social organizada desde un marco de igualdad social y derechos humanos, tiene el potencial para construir conocimiento valioso en torno a los problemas de salud de los hombres y relacionados con estos. El enriquecimiento de un corpus teórico sobre los varones y la salud colectiva facilitaría la identificación de ejes temáticos de política pública en salud con esta perspectiva y a diferentes niveles, los cuales podrían orientar acciones estratégicas dirigidas a esta población en congruencia con el cumplimiento de los proyectos de vida de las personas sin importar su condición, así como con la libre toma de decisiones de las colectividades mexicanas y latinoamericanas en función de sus necesidades e intereses.

\section{AGRADECIMIENTOS}

La elaboración de este estudio para obtener el grado de doctor, así como sus criterios éticos, fueron supervisados por la planta docente del propio Doctorado en Ciencias en Salud Colectiva de la División de Ciencias Biológicas y de la Salud, de la Universidad Autónoma Metropolitana Xochimilco, por el director de tesis y coautor de este texto, así como por las lectoras del comité del estudio. Contó con financiamiento de la beca del Consejo Nacional de Ciencia y Tecnología de México (CONACYT) para posgrados de calidad, durante el periodo 2010-2014. Se agradecen todas las facilidades otorgadas para la realización de este texto a la Universidad Autónoma del Estado de Hidalgo.

\section{REFERENCIAS BIBLIOGRÁFICAS}

1. Connell RW. Masculinidades. México: PUEG, UNAM; 2003.

2. Minello Martini N. Masculinidades: un concepto en construcción. Nueva Antropología. 2002;43(61): $11-30$.
3. de Keijzer Fokker B. Hombres, género y políticas de salud en México. En: Figueroa JA, (ed.). Políticas públicas y la experiencia de ser hombre. México: Centro de Estudios Demográficos, Urbanos y Ambientales de El Colegio de México; 2014.

4. Kaufmann M. Las experiencias contradictorias del poder entre los hombres. En: Valdés T, Olavarría J, (org.). Masculinidades: poder y crisis. Santiago: Ediciones de las Mujeres; 1997.

5. Bonino Méndez L. Deconstruyendo la "normalidad" masculina: Apuntes para una "psicopatología" de género masculino. Actualidad Psicológica. 1998;(253):17-20.

6. Fleiz CM. El malestar depresivo: una experiencia vivida por los hombres a través de su construcción de género [Tesis doctorado]. Psicología social y ambiental, Universidad Nacional Autónoma de México; 2010.

7. Sánchez J. Narraciones sobre la experiencia depresiva de hombres: Masculinidad y narcisismo. [Tesis doctorado]. Programa de Maestría y Doctorado en Psicología y Salud, Universidad Nacional Autónoma de México; 2015. 
8. Castro R, Bronfman M. Teoría feminista y sociología médica: bases para una discusión. Cadernos de Saúde Pública. 1993;9(3):375-394.

9. Figueroa Perea JG, Franzoni Lobo J. Introducción: Paternidad, espacios laborales, salud y educación a la luz de algunas políticas públicas. En: Figueroa Perea JG, (ed.). Políticas públicas y la experiencia de ser hombre: Paternidad, espacios laborales, salud y educación. México: Centro de Estudios Demográficos, Urbanos y Ambientales de El Colegio de México; 2014. p. 553-564.

10. Guinsberg Blak E. "Salud mental" y subjetividad como aspectos sustantivos de la salud colectiva. En: Jarillo Soto E, Guinsberg Blank E, (eds.). Temas y desafíos en salud colectiva. Buenos Aires: Lugar Editorial; 2007. p. 245-272.

11. Gilmore D. Hacerse hombre: Construcciones culturales de la masculinidad. Barcelona: Paidós Ibérica; 1994.

12. Organización Panamericana de la Salud. Masculinidades y salud en la Región de las Américas: Resumen. Washington DC: OPS; 2019.

13. Núñez G. Los estudios de género de los hombres y las masculinidades: ¿qué son y qué estudian? Culturales. 2016;4(1):9-31.

14. Jarillo Soto E, Garduño Andrade M, Guinsberg Blank E. Introducción. En: Jarillo Soto E, Guinsberg Blak E, (eds.). Temas y desafíos en salud colectiva. Buenos Aires: Lugar Editorial; 2007. p. 1-4.

15. de Keijzer Fokker B. La salud de los hombres: muchos problemas y pocas políticas. En: Rocha $\mathrm{T}$, Lozano I, (eds.). Debates y reflexiones en torno a las masculinidades: analizando los caminos hacia la igualdad de género. México: Facultad de Psicología de la Universidad Nacional Autónoma de México; 2014. p. 88-102.

16. Organización Mundial de Salud. Salud Mental [Internet]. 2015 [citado 1 feb 017]. Disponible en: https://tinyurl.com/wkfj4kw.

17. Organización Mundial de Salud. Determinantes sociales de la salud [Internet]. 2015 [citado 1 feb 2017]. Disponible en: https://tinyurl.com/ub6xflr.

18. García-Viniegras C, González I. La categoría bienestar psicológico: Su relación con otras categorías sociales. Revista Cubana de Medicina General Integral. 2000;16(6):586-592.

19. Tena O. Malestares laborales y condición masculina. En: Figueroa J, (ed.). Políticas públicas y la experiencia de ser hombre. México: El Colegio de México; 2014. p. 51-78.
20. Cruz S. Trabajo y subjetividad masculina. En: Jiménez $M$, Tena $O$, (eds.). Reflexiones sobre masculinidades y empleo. México: CRIM, UNAM; 2007.

21. Guinsberg E. La salud mental en nuestros tiempos de cólera: El sujeto de la salud mental a fin de siglo. México: La Casa de la Primera Imprenta de América; 1996.

22. Raventós S. Crisis económica y salud mental. SinPermiso [Internet]. 2010 [citado 29 mar 2019]. Disponible en: https://tinyurl.com/t96uluh.

23. Olavarría J. Globalización, género y masculinidades: Las corporaciones transnacionales y la producción de productores. Nueva Sociedad. 2008;(218):72-86.

24. Garduño A. Confluencia de la salud en el trabajo y la perspectiva de género: una nueva mirada [Tesis doctoral]. Ciudad de México: División de Ciencias Biológicas y de la Salud, Universidad Autónoma Metropolitana Unidad Xochimilco; 2011.

25. Vargas I, Caraveo J. Predictores clínicos de la presencia de psicopatología. Medicina Social. 2010;5(1):33-40

26. Tena O. Problemas afectivos relacionados con la pérdida, disminución y riesgo de pérdida del empleo en los varones. En: Tena $O$, Jiménez $M$, (eds.). Reflexiones sobre masculinidad y empleo. México: UNAM, CRIM; 2007. p. 357-375.

27. Bolaños F. El grupo de "Apoyo emocional al desempleo" en hombres: resultados de investigación. En: Figueroa J, (ed.). Políticas públicas y la experiencia de ser hombre: Paternidad, espacios laborales, salud y educación. México DF: El Colegio de México; 2014. p. 111-174.

28. de Keijzer B. Masculinidades, violencia, resistencia y cambio [Tesis doctoral]. Veracruz: Instituto de Investigaciones Psicológicas, Universidad Veracruzana; 2010.

29. Cantoral G. De las desigualdades de género a los malestares: la cotidianidad de mujeres y varones de San Cristóbal de las Casas, Chiapas. [Tesis doctoral]. San Cristóbal de las Casas: Universidad de Ciencias y Artes de Chiapas, Centro de Estudios Superiores de México y Centroamérica; 2014.

30. Borislavovna I. Depresión, autoestima y rasgos de personalidad asociados al género en estudiantes universitarios [Tesis doctoral]. México: División de Ciencias Biológicas y de la Salud, Universidad Autónoma Metropolitana; 2009. 
31. Granados J. Identidad y género: aportes para el análisis de la distribución diferenciada de los trastornos mentales. Salud Problema. 2001;6(1011):37-44.

32. López O, Blanco J. Desigualdad social e inequidades en salud: Desarrollo de conceptos y comprensión de relaciones. Salud Problema. 2003;8(14-15):7-16.

33. Castro R. Teoría social y salud. Buenos Aires: Lugar Editorial; 2011.

34. Laurell A. Sobre la concepción biológica y social del proceso salud-enfermedad. En: Rodríguez MI. Lo biológico y lo social. Washington DC: OPS, OMS; 1994. Serie Desarrollo de Recursos Humanos No. 101.

35. Burín M. Subjetividad femenina y salud mental. En: Pérez S, Ramírez J, Ravelo P. Género y salud femenina: Experiencias de Investigación en México. México: Universidad de Guadalajara, Instituto Nacional de Nutrición; 1995. p. 81-108.

36. Sandín B. El estrés: Un análisis basado en el papel de los factores sociales. International Journal of Clinical and Health Psychology. 2003; 3(1):141-157.

37. Molina T, Gutiérrez A, Hernández L, Contreras C. Estrés psicosocial: Algunos aspectos clínicos y experimentales. Anales de Psicología. 2008;24(2): 353-360.

38. Fierro A. Estrés, afrontamiento y adaptación. En: Hombrados MI, (ed.). Estrés y salud. Valencia: Promolibro; 1997. p. 9-38.

39. Bronfrenbrenner U. La ecología del desarrollo humano. Barcelona: Paidós; 1998.

40. Hernández R, Fernández P, Baptista P. Metodología de la investigación. 3ra ed. México: Mc Graw Hill Interamericana; 1991.
41. Andréu J. Las técnicas de análisis de contenido: una revisión actualizada. Sevilla: Fundación Centro de Estudios Andaluces; 2002.

42. Krueger R. Focus groups: A practical guide for applied research. 4th ed. Beverly Hills: Sage; 1991.

43. Sauto R, Boniolo P, Dalle P, Elbert R. Manual de metodología: Construcción del marco teórico, formulación de los objetivos y elección de la metodología. Buenos Aires: CLACSO; 2005.

44. de Keijzer B. El varón como factor de riesgo. En: Tuñón E, (coord.). Género y salud en el sureste de México. México: ECOSUR, Universidad Autónoma de Tabasco; 1998. p. 1-14.

45. Ramírez M. Hombres violentos: Un estudio antropológico de la violencia masculina. México: Instituto Jalisciense de las Mujeres, Plaza y Valdés; 2002.

46. Burin M, Meler I. Género: una herramienta teórica para el estudio de la subjetividad masculina. En: Burín M, Meler I, (eds.). Varones: Género y subjetividad masculina. Buenos Aires: Paidós; 2000. p. 15-71.

47. Bolaños F. La imagen de un fenómeno en movimiento: un acercamiento a la intervención con hombres que ejercen violencia contra su pareja. (Tesis de maestría). México DF: División de Ciencias Sociales y Humanidades, Universidad Autónoma Metropolitana Xochimilco; 2008.

48. Benson ML, Fox GL. When Violence Hits Home: How Economics and Neighborhood Play a Role [Internet]. Washington DC: Office of Justice Programs, National Institute of Justice; 2004 [citado 10 mar 2019]. Disponible en: https://tinyurl.com/tjem8uk.

49. Carmona P, Esquivel MI. Suma por la igualdad: Propuestas de agenda pública para implicar a los hombres en la igualdad de género. México: Género y Desarrollo, Colegio de Especialistas en Políticas Públicas y Estudios de Género, Red MenEngage: Cómplices por la equidad; 2018. 